\title{
Persistência da lactação e composição do leite em ovelhas leiteiras das raças Lacaune e East Friesian
}

\author{
Lactation persistency and milk composition in Lacaune and East Friesian dairy ewes
}

\author{
Elvis Ticiani ${ }^{\mathrm{I}}$ Eveline Caterine Sandri ${ }^{\mathrm{I}}$ Jonas de Souza $^{\mathrm{II}}$ Fernanda Batistel $^{\mathrm{II}}$ \\ Dimas Estrasulas de Oliveira ${ }^{\text {III }}$
}

\begin{abstract}
- NOTA -
RESUMO

O objetivo deste estudo foi avaliar a persistência da lactação e a composição do leite em ovelhas leiteiras das raças East Friesian e Lacaune. Foram usadas 21 ovelhas East Friesian

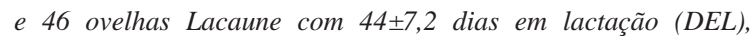
mantidas em pastagem de Panicum maximum Jacq. cv. 'Aruana' em um sistema rotacionado. A produção de leite (PL) foi medida a cada quatro dias durante todo o período experimental (92 dias). Amostras de leite foram coletadas no $1^{\circ}, 25^{\circ}, 50^{\circ}, 75^{\circ}$ e $92^{\circ}$ dia. As equações descrevendo a lactação foram diferentes (East Friesian: $P L=1,42-0,02 * D E L, r^{2}=0,20$; Lacaune: $P L=2,03-0,08 * D E L$,

analysis were collected on days 1, 25, 50, 75, and 92. The best fit prediction equations for $M Y$ were $M Y=1.42-0.02 * D I M, r^{2}=0.20$ for East Friesian; and MY=2.03-0.08* DIM, $r^{2}=0.22$ for Lacaune. At the beginning of the experimental period Lacaune MY was 30\% higher. Lacaune ewes showed lower persistency and higher milk yield (1.67 vs. $1.35 \mathrm{~kg} \mathrm{day}^{-1}, \mathrm{P}<0.001$ ), milk fat yield (114.80 vs. $102.85 \mathrm{~g} \mathrm{day}^{-1}, P<0.001$ ) and protein yield (82.82 vs. $73.10 \mathrm{~g} \mathrm{day}^{-1}$, $P<0.001)$. East Friesian ewes had greater milk fat (7.31 vs. 6.86\%, $P<0.0008)$ and protein concentrations (5.18 vs. $4.93 \%, P<0.001)$. Overall, the East Friesian ewes showed more persistency than Lacaune, but the milk yield and milk yield composition was greater in Lacaune.
\end{abstract} $\left.r^{2}=0,22\right)$. Ao início do período experimental, a produção de leite das ovelhas Lacaune foi $30 \%$ superior. As ovelhas Lacaune apresentaram menor persistência, maiores produções de leite (1,67 vs. $\left.1,35 \mathrm{~kg} \mathrm{dia}^{-1}, P<0,001\right)$, de gordura $(114,80$ vs. $102,85 \mathrm{~g}$ dia $\left.^{-1}, P<0,001\right)$ e de proteína (82,82 vs. $73,10 \mathrm{~g}$ dia $\left.^{-1}, P<0,001\right)$. As ovelhas East Friesian apresentaram maiores teores de gordura (7,31 vs. $6,86 \%, P<0,0008)$ e proteína $(5,18$ vs. 4,93\%, $P<0,001)$. No geral, as ovelhas East Friesian mostraram maior persistência, mas a produção de leite e componentes do leite foram maiores para as ovelhas Lacaune.

Palavras-chave: leite ovino, pastagem tropical, produção de leite.

\section{ABSTRACT}

The objective of this study was to evaluate the lactation persistency and milk composition in East Friesian and Lacaune dairy ewes. Twenty one East Friesian and forty six Lacaune ewes on $44 \pm 7.2$ days in milk (DIM) were used in a rotational system grazing paddocks of Panicum maximum jacq. cv. 'Aruana'. Milk yield (MY) was measured every four days throughout the experiment (92 days). Milk samples for composition
Key words: milk yield, ovine milk, tropical pasture.

Os ovinos constituem a segunda espécie mais explorada na pecuária mundial (FAO, 2010) e, na região oeste de Santa Catarina, sua exploração vem se expandindo, com destaque às raças leiteiras. Dentre as características desejáveis para os animais de aptidão leiteira, além da alta produção diária que influencia na quantidade de leite, a persistência da lactação vem ganhando importância, devido à relação direta entre essa característica e alguns aspectos econômicos, com impacto na rentabilidade da atividade.

A persistência da lactação pode ser definida como a capacidade de o animal manter sua produção de leite após atingir o pico de produção (COBUCI

'Curso de Pós-graduação em Ciência Animal, Universidade do Estado de Santa Catarina (UDESC), Lages, SC, Brasil.

${ }^{\text {IIC } C u r s o ~ d e ~ P o ́ s-g r a d u a c ̧ a ̃ o ~ e m ~ C i e ̂ n c i a ~ A n i m a l ~ e ~ P a s t a g e n s, ~ U n i v e r s i d a d e ~ d e ~ S a ̃ o ~ P a u l o ~(U S P), ~ P i r a c i c a b a, ~ S P, ~ B r a s i l . ~}$

IIIPrograma de Pós-graduação em Ciência Animal, Universidade do Estado de Santa Catarina (UDESC), 88520-000, Lages, SC, Brasil. E-mail: dimas.oliveira@udesc.br. *Autor para correspondência. 
et al., 2003). No período inicial, maiores produções exigem um esforço fisiológico maior por parte dos animais, causando, frequentemente, diminuição do desempenho reprodutivo e o aparecimento de distúrbios metabólicos. Moderadas produções neste período, combinadas com maiores níveis de persistência ao longo da lactação são desejáveis, pois predispõe a menor ocorrência de desordens metabólicas e podem representar maior produção durante a lactação (COBUCI et al., 2003).

A raça Lacaune é bastante difundida no Brasil, destacando-se por alta produção de leite, aliada à elevada adaptabilidade, especialmente para a região sul, mas, devido ao aumento do coeficiente de endogamia, outras raças como a East Friesian, também conhecida como Frisona Milchschaf, vêm sendo introduzidas devido à rusticidade, boa produção de leite e número de cordeiros desmamados.

Em ovinos, há uma escassez de estudos avaliando o efeito racial sobre a persistência de lactação. Assim, o objetivo deste estudo foi comparar a persistência da lactação e a composição do leite no período pós-pico de produção entre ovelhas leiteiras das raças East Friesian e Lacaune.

O experimento foi realizado no município de Guatambu - SC, situado a $27^{\circ} 07^{\prime}$ de latitude Sul, $52^{\circ} 44^{\prime}$ de longitude Oeste e $578 \mathrm{~m}$ de altitude, por um período de 92 dias entre os meses de agosto e novembro de 2010.

Foram utilizadas sessenta e sete ovelhas multíparas, imediatamente após o desmame dos cordeiros, sendo 21 da raça East Friesian e 46 da raça Lacaune, com média de 44 $\pm 7,2$ dias em lactação (DEL). Os animais foram separados de um rebanho maior, de acordo com o peso e a produção prévia de leite. Os pesos médios foram de 63,5 $\pm 6,5$ e $66,4 \pm 6,9 \mathrm{~kg}$ para as raças East Friesian e Lacaune, respectivamente. As ovelhas foram mantidas em piquetes de capim Aruana (Panicum maximum Jacq. cv. 'Aruana') com 0,3 hectares em sistema intermitente de pastejo, com três dias de ocupação e 12 de descanso, onde a massa de forragem média no período foi 2843,6kg de matéria seca por hectare. Os animais receberam, individualmente, $1 \mathrm{~kg}$ (base seca) de concentrado dia $^{-1}$, composto por $55,0 \%$ de milho moído, 37,0\% de farelo de soja, 1,0\% de bicarbonato de sódio, $2 \%$ de sais de cálcio de óleo de palma (Agelac 84, Raupp, Chapecó, Santa Catarina, Brasil) e 5,0\% de núcleo vitamínico-mineral (Nutrimasa Agroindustrial Alimentos, Chapecó, Brasil), o qual foi formulado utilizando-se o software SRNS (TEDESCHI et al., 2010) para suprir as exigências nutricionais, de acordo com o NRC (2007).
A ordenha foi mecânica às $6 \mathrm{~h}$ e $17 \mathrm{~h}$ e a pesagem individual do leite foi realizada a cada quatro dias nas duas ordenhas. A produção diária foi determinada por meio da soma das duas medidas. As amostras de leite para análise da composição (proteína, gordura, lactose e sólidos totais) e contagem de células somáticas (CCS) foram coletadas no $1^{\circ}$, 25ํㅡㄴ $50^{\circ}, 75^{\circ}$ e $92^{\circ}$ dia do período experimental e as amostras foram compostas, proporcionalmente, de acordo com as duas ordenhas diárias e estocadas a $4^{\circ} \mathrm{C}$ com conservante (bromopol, D \& F Control Systems Inc., San Ramon, CA), por um dia, antes de serem analisadas no laboratório de serviço de análises de rebanhos leiteiros (SARLE) da Universidade de Passo Fundo, por espectroscopia no infravermelho (IDF, 2000), utilizando o aparelho Bentley 2000. A contagem de células somáticas (CCS) foi determinada através de citometria de fluxo (IDF, 2006), com o uso do aparelho Bentley BactoCount IBC.

A análise estatística foi realizada pelo pacote estatístico SAS (SAS Institute, 2009), por meio do procedimento MIXED para as medidas repetidas, como a produção de leite, concentração de proteína, gordura, lactose e CCS. Os procedimentos GLM e REG foram usados para verificar a adequacidade dos modelos de regressão e a existência de diferença entre as curvas de lactação das raças, através do comando solution. Os interceptos (a) e coeficientes angulares (b) das duas equações foram comparados de acordo com o método descrito por NETER \& WASSERMAN (1996), adotando-se um nível de significância de 5\%.

Os interceptos e coeficientes angulares das duas equações foram diferentes entre si $(\mathrm{P}<0,001)$, evidenciando que as curvas de lactação foram distintas entre as raças. As equações para a produção de leite (PL) foram: para a raça East Friesian: $\mathrm{PL}=1,42-0,002 * \mathrm{DEL}\left(\mathrm{r}^{2}=0,02\right)$ com erro padrão de 0,035 e 0,0007 , para intercepto e coeficiente angular, respectivamente; para a raça Lacaune: $\mathrm{PL}=2,03$ $0,008 *$ DEL $\left(r^{2}=0,22\right)$, com erros padrão de 0,025 e 0,0005 para o intercepto e coeficiente angular, respectivamente.

A produção de leite da raça Lacaune ao início do período experimental foi 30\% superior à da raça East Friesian. Entretanto, as ovelhas Lacaune apresentaram queda mais acentuada ao decorrer da lactação, caracterizando menor persistência, com menor capacidade em manter a sua produção. De acordo com os coeficientes angulares, a queda diária da produção foi quatro vezes menor nas ovelhas East Friesian (2 vs. $8 \mathrm{~g} \mathrm{dia}{ }^{-1}$ ) e, em um estudo com vacas leiteiras, COBUCI et al. (2003) obtiveram resultados semelhantes, onde animais com maiores produções 
até o pico de lactação apresentaram declínio de lactação mais acentuado, quando comparadas com vacas de menores produções. Corroborando os resultados obtidos neste experimento, ORAVCOVÁ et al. (2006) constataram maior produção de leite para as ovelhas Lacaune, quando avaliaram curvas de produção de três raças distintas (Tsigai, Improved Valachian e Lacaune).

A produção média diária (1,35 vs. $\left.1,67 \mathrm{~kg} \mathrm{dia}^{-1}, \mathrm{P}<0,001\right)$ e total de leite $(124,20 \mathrm{vs}$. $153,64 \mathrm{~kg}, \mathrm{P}<0,02$ ) no período experimental foram, respectivamente, 18 e 19,2\% inferiores para as ovelhas East Friesian. A maior produção total de leite das ovelhas Lacaune é atribuída à alta produção ao início do período experimental, refletindo uma maior produção no pico de lactação. Entretanto, elas apresentaram uma queda mais acentuada, demonstrando menor persistência da lactação. BENCINI \& PULINA (1997) descreveram que em ovinos o declínio da lactação pós-pico pode ocorrer mais ou menos rapidamente em função do potencial individual para produção de leite, sendo negativa a correlação entre produção no pico de lactação e a persistência. Nesse sentido, CAPPIO-BORLINO et al. (1997) observaram que ovelhas com maior produção durante o pico de lactação tiveram menor persistência.

Como os animais estavam todos sobre o mesmo manejo, a menor persistência na raça Lacaune está ligada a sua maior produção no início do experimento, exigindo mais do animal, causando um maior desgaste em função da maior exigência metabólica, dificultando a manutenção da taxa de renovação celular e a produção por célula secretora no epitélio mamário e, por consequência, havendo maior decréscimo na produção de leite. Conforme AKERS (2006), a produção de leite é influenciada pelo número de células secretoras na glândula mamária e pela atividade sintética de cada célula secretora. Após o parto, a manutenção do epitélio secretor é o fator chave na determinação da persistência de lactação e no total de leite produzido, sendo a manutenção da síntese de leite e secreção controlada por uma combinação de fatores de regulação locais e sistêmicos.

As diferenças entre a composição de leite estão na tabela 1. A raça East Friesian apresentou maiores teores de gordura e proteína do leite. Em contrapartida, a produção diária (g) de gordura, proteína e lactose foram, respectivamente, 11,6, 13,3 e 20,3\% maiores para as ovelhas Lacaune em função da sua maior produção de leite.

A raça Lacaune, apesar de ter apresentado menor concentração de proteína e gordura no leite, produziu mais gordura, proteína e lactose, devido à maior produção de leite durante o período de estudo. Em outro estudo, ARRANZ et al. (1993) observaram que a utilização da raça Lacaune em cruzamentos F1 Lacaune x Churra, resultou em aumento de 55\% na produção de leite em relação à raça pura Churra. No entanto, os teores de gordura e proteína foram 51 e 52\% inferiores, respectivamente, mostrando diferenças genéticas.

As ovelhas Lacaune apresentaram maior produção de leite, gordura, proteína e lactose. Entretanto, a persistência da lactação foi maior para os animais da raça East Friesian, bem como os teores de proteína e gordura no leite.

Tabela 1 - Produção e composição média do leite de ovelhas leiteiras das raças Lacaune e East Friesian (n=67).

\begin{tabular}{|c|c|c|c|c|}
\hline & Lacaune & East Friesian & $\begin{array}{c}\text { Erro Padrão da } \\
\text { Média }\end{array}$ & $\mathrm{P}^{*}$ \\
\hline Produção total de leite** (kg) & 153,64 & 124,20 & 7,40 & 0,02 \\
\hline Produção de leite $\left(\mathrm{kg} \mathrm{dia}^{-1}\right)$ & 1,67 & 1,35 & 0,02 & 0,0001 \\
\hline$\%$ gordura & 6,86 & 7,31 & 0,11 & 0,0008 \\
\hline \% proteína & 4,93 & 5,18 & 0,03 & 0,0001 \\
\hline$\%$ lactose & 4,65 & 4,65 & 0,02 & 0,89 \\
\hline Gordura (g dia ${ }^{-1}$ ) & 114,80 & 102,85 & 2,89 & 0,001 \\
\hline Proteína (g dia ${ }^{-1}$ ) & 82,82 & 73,10 & 1,94 & 0,0001 \\
\hline Lactose (g dia ${ }^{-1}$ ) & 80,00 & 66,50 & 2,04 & 0,0001 \\
\hline
\end{tabular}

Valor de P; **produção de leite em quilos no período experimental. 


\section{AGRADECIMENTOS}

Os autores agradecem ao Sr. Paulo Gregianin e família, por abrirem as portas de sua propriedade rural e colaborarem para a obtenção de todas as medidas. Os autores pagaram com recursos próprios todos os demais custos.

\section{COMITÊ DE ÉTICA E BIOSSEGURANÇA}

Os autores declaram que os animais utilizados neste experimento foram tratados com ética e não sofreram nenhum tratamento invasivo ou que causasse dor e/ou desconforto. O trabalho e todos os métodos nele empregados são de total responsabilidade dos autores.

\section{REFERÊNCIAS}

AKERS, R.M. Major advances associated with hormone and growth factor regulation of mammary growth and lactation in dairy cows. Journal of Dairy Science, v.89, p.1222-1234, 2006. Disponível em: <http://dx.doi.org/10.3168/jds.S00220302(06)72191-9>. Acesso em: 02 ago. 2012. doi: 10.3168/jds. S0022-0302(06)72191-9.

ARRANZ, J. et al. Produccion y calidad de La leche de ovejas F1 Lacaune x Churra y Churras explotada sen Tierra de Campos (Palencia). Información Técnica Económica Agraria Extra, v.12, p.27-29, 1993.

BENCINI, F.; PULINA, G. The quality of sheep milk: a review. Wool Technology and Sheep Breeding, v.45, p.182-220, 1997. Disponível em: <http://www.publish.csiro.au/paper/ EA96014\#>. Acesso em: 21 jul. 2012. doi: 10.1071/EA96014.

CAPPIO-BORLINO, A. et al. Lactation curves of Valle del Belice dairy ewes for yields of milk, fat, and protein estimates with Test Day Models. Journal of Dairy Science, v.80, p.3023-3029,
1997. Disponível em: <http://dx.doi.org/10.3168/jds.S00220302(97)76269-6>. Acesso em: 21 jul. 2012. doi: 10.3168/jds. S0022-0302(97)76269-6.

COBUCI, J.A. et al. Persistência na lactação: uma revisão. Archivos Latino americanos Produccion Animal, v.11, p.163-173, 2003. Disponível em: <http://ojs.alpa.org.ve/index. php/ojs_files/article/viewFile/49/52>. Acesso em: 21 jul. 2012.

FAO. Boletim estatístico. Food and Agriculture Organization of the United Nations. 2010. 88 p. Disponível em: < https:// www.fao.org.br/download/OECDFAO_AgriculturalOutlook 20102019.pdf>. Acesso em: 22 jul. 2012.

NRC (NATIONAL RESEARCH COUNCIL). Nutrient requirements of small ruminants: sheep, goats, cervids, and new world camelids. Washington, DC, 2007. 362p.

NETER, J.; WASSERMAN, W. Topics in regression analysis. In: NETER, J. et al. (Ed.). Applied linear statistical models. New York: Springer, 1996. Cap.5, p.160-169.

ORAVCOVÁ, M. et al. Factors affecting milk yield and ewe's lactation curves estimated with test-day models. Czech Journal Animal Science, v.51, p.483-490, 2006. Disponível em: <http://www.agriculturejournals.cz/publicFiles/52342. pdf $>$. Acesso em: 21 jul. 2012.

SAS Institute Inc. SAS/STAT: User's guide. Version 9.2.ed. Cary, NC, 2009. 240p.

TEDESCHI, L.O. et al. A nutrition mathematical model to account for dietary supply and requirements of energy and nutrients for domesticated small ruminants: the development and evaluation of the small ruminant nutrition system. Small Ruminant Research, v.89, p.174-184, 2010. Disponível em:<http://download.journals.elsevierhealth.com/pdfs/ journals/0921-4488/PIIS0921448809003137.pdf $>$. Acesso em: 21 jul. 2012. 